\title{
Growth of Carbon Nanotubes on Carbon/Cobalt Films with Different $\mathrm{sp}^{2} / \mathrm{sp}^{3}$ Ratios
}

\author{
Naiyun Xu, ${ }^{1}$ Siu Hong Tsang, ${ }^{2}$ Beng Kang Tay, ${ }^{1}$ \\ Edwin Hang Tong Teo, ${ }^{1}$ and Chee Mang $\mathbf{N g}^{3}$ \\ ${ }^{1}$ School of Electrical and Electronic Engineering, Nanyang Technological University, 50 Nanyang Avenue, Singapore 639798 \\ ${ }^{2}$ Temasek Laboratories@NTU, 50 Nanyang Avenue, Singapore 639798 \\ ${ }^{3}$ GLOBALFOUNDRIES Singapore Pte. Ltd., Singapore 738406
}

Correspondence should be addressed to Naiyun Xu; e090033@e.ntu.edu.sg and Beng Kang Tay; ebktay@ntu.edu.sg

Received 10 May 2013; Accepted 7 June 2013

Academic Editor: Xingbin Yan

Copyright (C) 2013 Naiyun Xu et al. This is an open access article distributed under the Creative Commons Attribution License, which permits unrestricted use, distribution, and reproduction in any medium, provided the original work is properly cited.

\begin{abstract}
The need of barrier layer such as $\mathrm{SiO}_{2}$ for carbon nanotubes (CNTs) growth limits their performance in electronic applications. In this study, conductive carbon/metal (carbon/cobalt-C:Co) composite films with the same metal content, but different $\mathrm{sp}^{2} / \mathrm{sp}^{3}$ ratios, were deposited using dual-source filtered cathodic vacuum arc (FCVA) technique. Three different C:Co composite films were deposited at different temperatures; visible Raman spectroscopy indicates that the $\mathrm{sp}^{2}$-rich C:Co composite film forms at high temperature $\left(500^{\circ} \mathrm{C}\right)$, and high-resolution transmission electron microscopy (HRTEM) shows the formation of conducting graphitic-like $\mathrm{sp}^{2}$ clusters and with Co nanoclusters embedded within them. Electrical measurement shows a significant decrease in film resistivity as $\mathrm{sp}^{2} / \mathrm{sp}^{3}$ ratio increases. CNTs were successfully grown on the composite films by plasma-enhanced vapor deposition (PECVD) approach. Scanning electron microscopy (SEM) shows minor effect on the density of CNTs by varying the $\mathrm{sp}^{2} / \mathrm{sp}^{3}$ ratio. The dependence of defect level of the as-grown CNTs is found to reduce as $\mathrm{sp}^{2} / \mathrm{sp}^{3}$ ratio increases.
\end{abstract}

\section{Introduction}

Carbon nanotubes (CNTs) have attracted a lot of attention in the fields of nanoscience and nanotechnology because of their superior physical, electrical, and thermal properties $[1,2]$. A substantial amount of work has been done to promote them in the industry, and one of the requirements is growth of CNTs on conductive metal or substrates [3, 4]. The conventional way of growing CNTs is a multistep process, the first of which is to deposit a barrier layer, which can be an insulating material such as silicon oxide $\left(\mathrm{SiO}_{2}\right)$ or conductive material such as titanium nitride [5]. Secondly it requires the deposition of a catalyst layer such as nickel $(\mathrm{Ni})$, cobalt $(\mathrm{Co})$, or iron $(\mathrm{Fe})$. However, the effective electrical conductivity of the CNTs is higher when CNTs are grown directly on a conductive substrate [6]. An alternative approach to eliminate the use of barrier layer during growth is to deposit amorphous carbon a-C metal (C:Me) composite film, such as $\mathrm{C}: \mathrm{Ni}, \mathrm{C}: \mathrm{Fe}$, and $\mathrm{C}: \mathrm{Co}$, as the catalyst layer.

Previous studies had shown that composite film serving as catalyst layer results in better density control of CNTs $[7,8]$ and also better performance in CNTs field emitter array (FEA) applications $[9,10]$. Other than serving as the catalyst layer of CNTs growth, another advantage of incorporation of metal within C film is to increase the conductivity of the film. Takeno et al. found that the electrical conductivity is proportional to the amount of metal incorporated into the C:Me composite film [11-13]. However the focus was only on tuning the metal content of the film. The relationship between the CNTs growth and the intrinsic properties of C:Me composite film, such as the $\mathrm{sp}^{2} / \mathrm{sp}^{3}$ ratio, is not well understood yet. Recent work has shown that by in-situ thermal annealing and ex situ laser annealing, $\mathrm{sp}^{2}$-rich high electrical conducing nanostructured C film can be synthesized [14-17], which can 


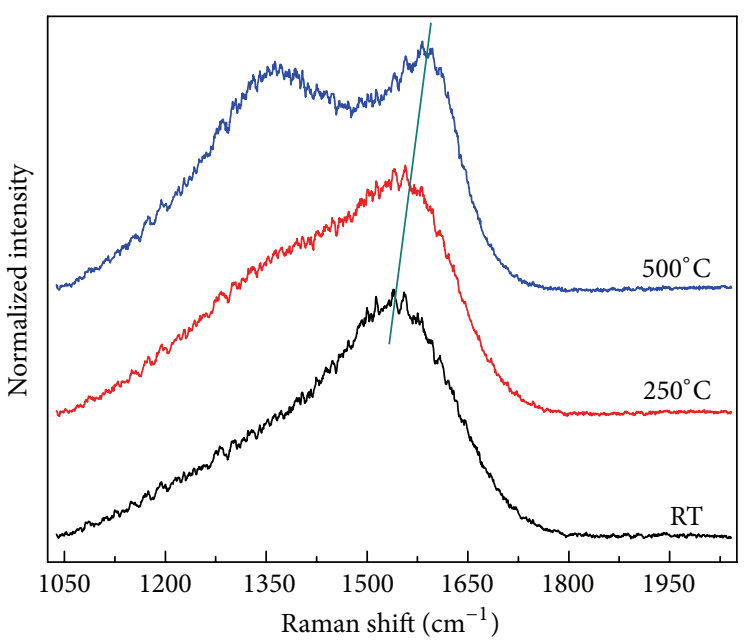

(a)

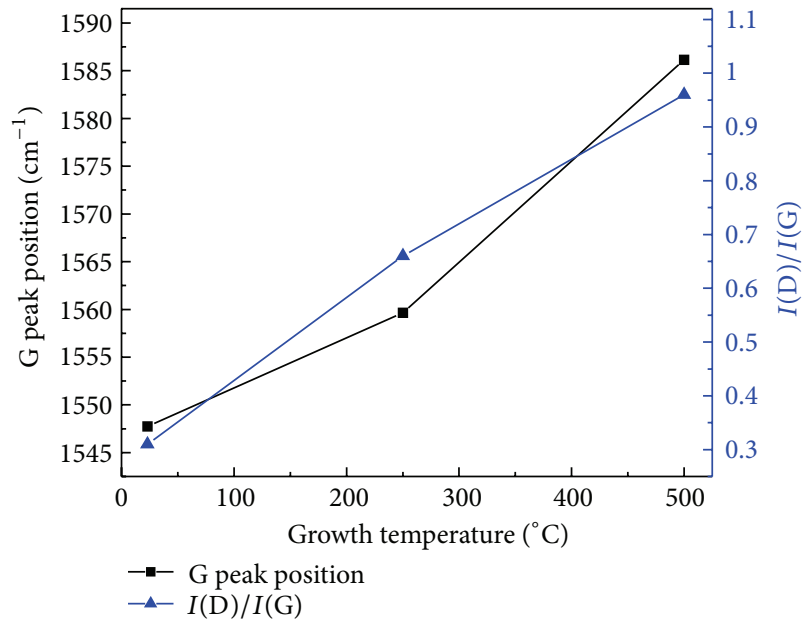

(b)

FIgURE 1: (a) Raman spectra of C:Co composite film grown using different growth temperatures and (b) Raman features as a function of growth temperature.

then be adopted in future electronic applications. Hence the electrical properties of C:Me composite film can be varied by only changing the $\mathrm{sp}^{2} / \mathrm{sp}^{3}$ ratio of the amorphous carbon.

In this work, C:Co composite film has been adopted as the catalyst layer of CNTs growth. We reported the feasibility of CNTs growth on conducting C:Co composite film, by only varying the $\mathrm{sp}^{2} / \mathrm{sp}^{3}$ ratio of the film. It adequately shows that CNTs can be grown on a conducting catalyst layer without the use of a barrier layer.

\section{Materials and Methods}

C:Co composite films were deposited on n-doped (100) silicon wafer, which was firstly cleaned using acetone, followed by ultrasonic isopropanol (IPA) to remove the surface particles. The films were deposited using dual-source FCVA which consists of two off-plane double bend (OPDB) filtering bends, each of them is connected to individual cathode source as described in our past work [18]. In this work, 99.999\% pure graphite rod and $99.9 \%$ pure nickel rod were used to form the $\mathrm{C}$ and Co ions. The composition was controlled by the arc current of the cathode source which was fixed at $70 \mathrm{~A}$ for $\mathrm{C}$ and $120 \mathrm{~A}$ for Co. Film depositions were carried out in the vacuum $\left(\sim 10^{-5}\right.$ Torr), and no bias was applied to the substrate. The substrate heating temperature was varied from room temperature to $500^{\circ} \mathrm{C}$ to obtain the various $\mathrm{sp}^{2} / \mathrm{sp}^{3}$ ratios. The thickness of different C:Co composite films was measured to be $50 \mathrm{~nm}$ using the Tencor P-10 surface profilometer. The resistance of different C:Co composite films was measured using a cascade of $200 \mathrm{~nm}$ probe station with a Hewlett Packard 4156A precision semiconductor parameter analyzer, with a voltage step of $0.01 \mathrm{~V}$.

The three C:Co composite films were then cut into a dimension of $1 \mathrm{~cm}$ by $1 \mathrm{~cm}$ and placed into a plasma-enhanced chemical vapor deposition (PECVD) chamber where the CNT growth would be carried out. The CNT growth was performed at $600^{\circ} \mathrm{C}$ with a plasma power of $85 \mathrm{~W}$ for $30 \mathrm{~min}$. The ramp rate was set at maximum. The heater stage reached $600^{\circ} \mathrm{C}$ in less than $10 \mathrm{sec}$, and the carbon feedstock gas $\left(\mathrm{C}_{2} \mathrm{H}_{2}\right)$ was immediately introduced to reduce the influence of annealing on the samples. The pressure in the chamber during CNT growth was maintained at 4.5 Torr with a $\mathrm{C}_{2} \mathrm{H}_{2} / \mathrm{NH}_{3}$ gas ratio of $1: 5$.

The atomic fraction of Co within the films was estimated using energy dispersive X-ray spectroscopy (EDX). In this work, Co is detected to be $\sim 5 \%$ in atomic ratio for all three films. Before CNT growth, the microstructure of different C:Co composite films was characterized using WITec visible Raman spectroscopy with a $532 \mathrm{~nm}$ diode-pumped solid state laser. The obtained Raman spectra were fitted using a Breit-Wigner-Fano (BWF) line shape for the G band and a Lorentzian line shape for $\mathrm{D}$ band if the spectra cannot be fitted by only the BWF line shape $[19,20]$. To confirm the formation of graphitic-like sp ${ }^{2}$ clusters, JEOL JEM 2100 highresolution transmission electron microscopy (HRTEM) was used. The images of the grown CNTs were acquired using scanning electron microscopy (SEM), and the CNT quality was also characterized using visible Raman spectroscopy.

\section{Results and Discussions}

Figure 1(a) shows the Raman spectra of C:Co composite films deposited using different substrate temperatures. The main changes of the Raman spectra are the shift of $G$ peak position and the increase in $D$ peak density. The $G$ band relates to both breathing and stretching modes of $\mathrm{sp}^{2}$ bonds, and the $\mathrm{D}$ band only reflects the existence of the breathing mode of $\mathrm{sp}^{2}$ bonds, which are normally in the form of nanometer-size graphitic-like clusters $[19,20]$. The spectra of the C:Co composite film at room temperature show that only one peak and a neighbor peak at around $1350 \mathrm{~cm}^{-1}$ started to emerge with increasing substrate temperature. 


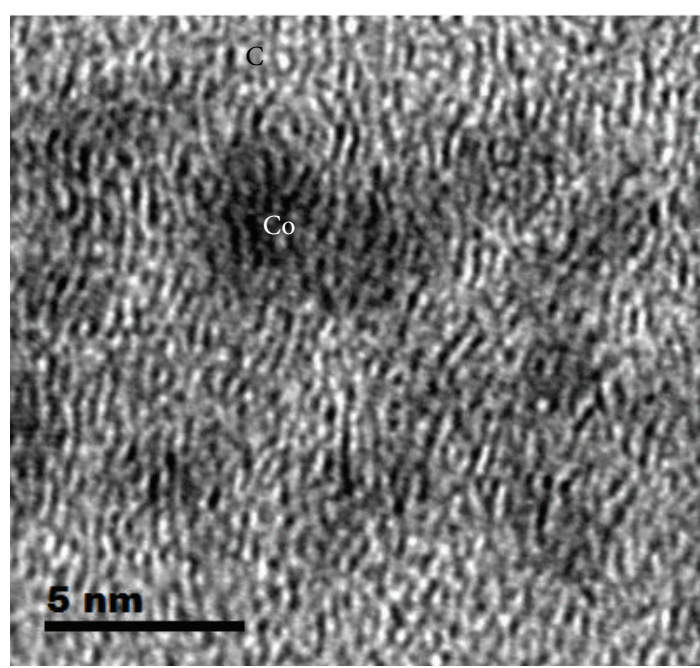

FIgURE 2: Cross section view of HRTEM image of C:Co composite film deposited at $500^{\circ} \mathrm{C}$.

The microstructure subjected to different growth temperatures is shown in Figure 1(b) - the rightward shift of G peak position is due to the conversion of $\mathrm{sp}^{3}$ bonding to $\mathrm{sp}^{2}$ bonding [14,20,21]. Based on the three-stage model [20], the film grown under RT is estimated to be $30 \%$ in $\mathrm{sp}^{2}$ content, and as the growth temperature increases, the $\mathrm{sp}^{2}$ content in the film rises to more than $80 \%$. Besides the rise in $\mathrm{sp}^{2}$ content, the six-ring graphitic-like $\mathrm{sp}^{2}$ bonds also become dominant, which is shown by the increase in $I(\mathrm{D}) / I(\mathrm{G})$ ratio [20], in Figure 1(b).

To confirm the formation of the graphitic-like $\mathrm{sp}^{2}$ clusters, HRTEM analysis has been performed on the C:Co composite film deposited at $500^{\circ} \mathrm{C}$. Figure 2 shows the HRTEM image of the film; due to higher density of Co atoms $\left(8.9 \mathrm{~g} / \mathrm{cm}^{3}\right)$ compared to the $\mathrm{C}$ atoms $\left(3.515 \mathrm{~g} / \mathrm{cm}^{3}\right.$ for diamond, $2.267 \mathrm{~g} / \mathrm{cm}^{3}$ for graphite, and $1.8 \sim 2.1 \mathrm{~g} / \mathrm{cm}^{3}$ for amorphous carbon), fewer electrons are able to transmit from Co region; hence the dark contrast on Co nanoclusters is presented in the HRTEM image. It clearly shows that the Co nanoclusters are embedded within the graphiticlike clusters. The graphitic-like clusters form the electronconducting paths, and the free electrons contributed by the Co also enhance the electrical conductivity of the film [22].

The changes in the microstructure of C:Co composite film influence the electrical properties of the film as represented by the $I-V$ curve of these three films in Figure 3. The film grown under RT has high resistance of $\sim 10^{9} \mathrm{ohm}$, and the resistance reduces with the growth temperature. The film grown under $500^{\circ} \mathrm{C}$ has a much lower resistance of about $10^{1} \mathrm{ohm}$. The reduction of resistance is attributed to the increase in $\mathrm{sp}^{2}$ content, the formation of more graphitic-like $\mathrm{sp}^{2}$ clusters, which has been reported in a previous study [14-16], and also the incorporation of Co nanoclusters.

Figures 4(a), 4(b), and 4(c) show the CNTs grown on different C:Co composite films. CNTs of the same length $(\sim 1 \mu \mathrm{m})$ can be synthesized on all these three types of C:Co

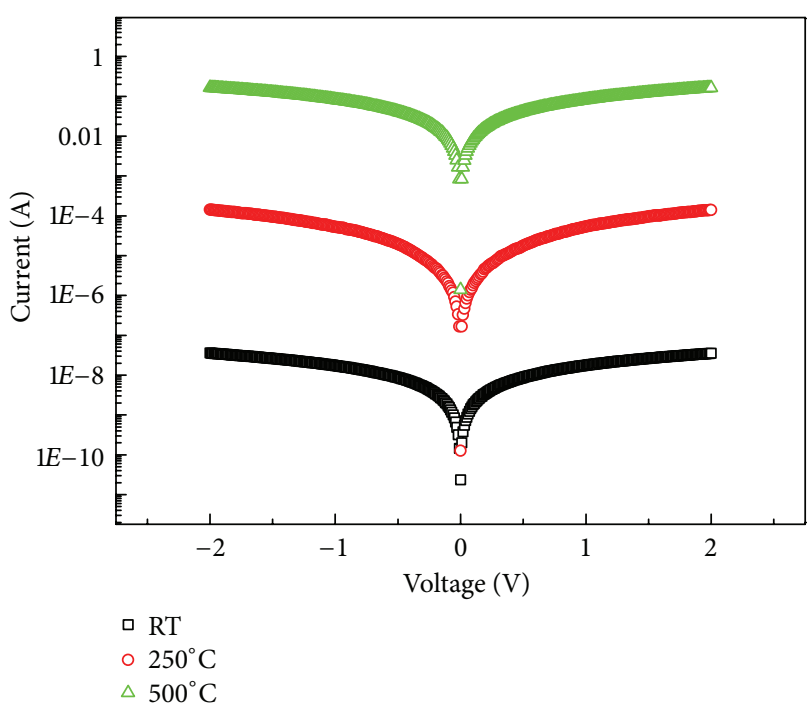

FIgURE 3: $I-V$ characteristic of C:Co composite films grown using different growth temperatures.

composite film. However, the density of CNTs does not have a significant change among these three kinds of C:Co composite film. Zhang et al. have reported that the density of CNTs grown on C:Me film has a strong relation with the content of metal [7]. In this work, it was demonstrated that the initial $\mathrm{sp}^{2} / \mathrm{sp}^{3}$ ratio does not affect the density of CNTs grown on the C:Co composite film. The quality of the CNTs is characterized and shown in Figure 5. The two peaks detected in the spectra are $D$ peak and $G$ peak which fall in the range of $1370 \sim 1400 \mathrm{~cm}^{-1}$ and $1580 \sim 1600 \mathrm{~cm}^{-1}$. Unlike C film, D peak for CNTs represents defects and G peak is an indication of crystalline graphite [23]. The inserted table lists the $I(\mathrm{D}) / I(\mathrm{G})$ ratios of these CNTs. CNTs 3 has the lowest ratio which indicates the lowest defect level. Although the defect level is desired to be zero, it is difficult to be eliminated in the PECVD process [24].

\section{Conclusions}

C:Co composite films with the same Co content but different initial $\mathrm{sp}^{2} / \mathrm{sp}^{3}$ ratios were deposited using dual-source FCVA technique, with varying growth temperatures. The change in microstructure of the film leads to the formation of the $\mathrm{sp}^{2}$ rich C:Co composite film, with the presence of conducting graphitic-like $\mathrm{sp}^{2}$ cluster. The electrical resistance is reduced to approximately $10^{1} \mathrm{ohm}$. CNTs can be successfully synthesized on C:Co composite film regardless of the change of initial $\mathrm{sp}^{2} / \mathrm{sp}^{3}$ ratio of the film. There is no clear evidence to show the influence of initial $\mathrm{sp}^{2} / \mathrm{sp}^{3}$ ratio on the density of CNTs grown on C:Co composite film; however the quality, such as defect level, is shown to be dependent on the initial $\mathrm{sp}^{2} / \mathrm{sp}^{3}$ ratio of the C:Co composite film, which can be reduced by using film with higher initial $\mathrm{sp}^{2} / \mathrm{sp}^{3}$ ratio. 


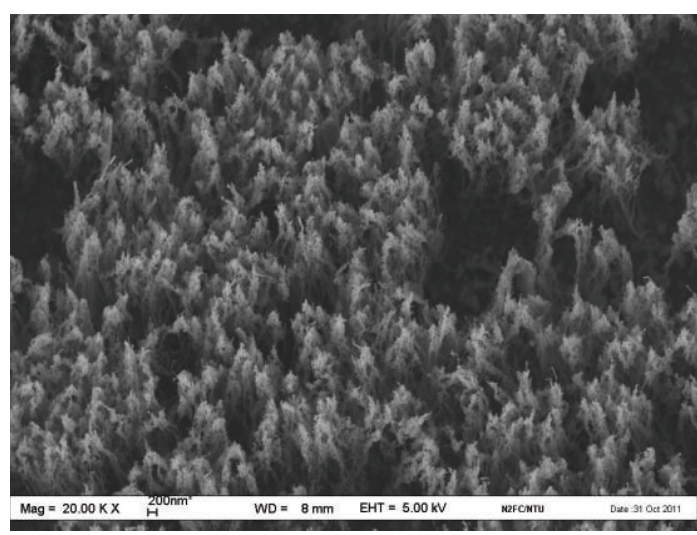

(a)

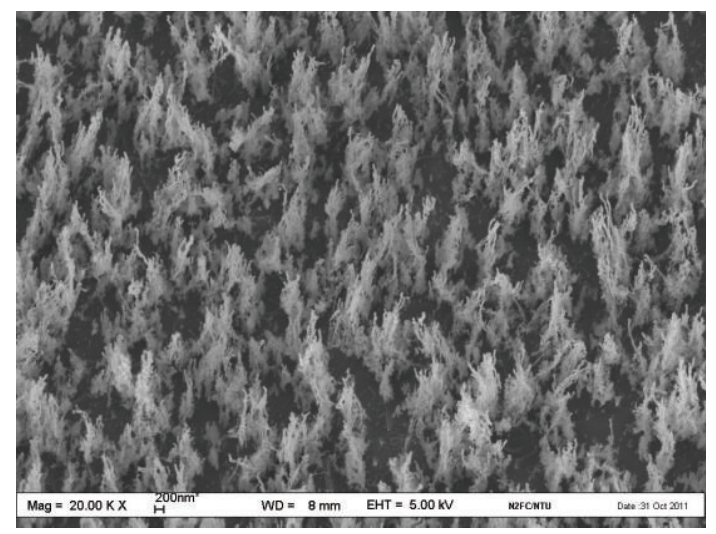

(b)

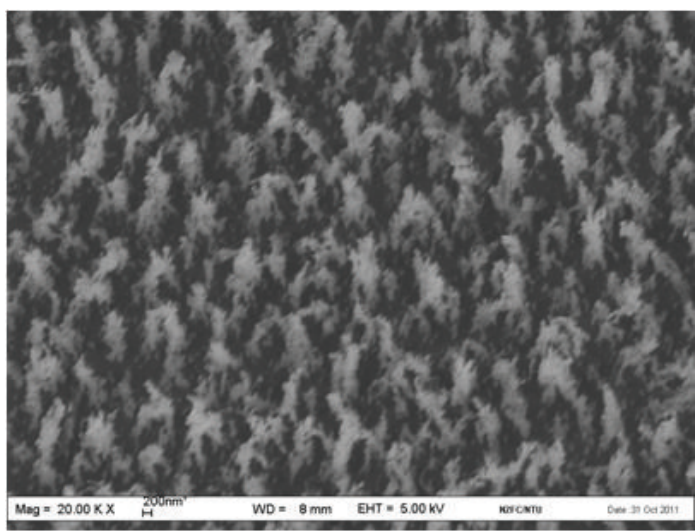

(c)

Figure 4: SEM images of CNTs grown on different C:Co composite films: (a) RT, (b) $250^{\circ} \mathrm{C}$, and (c) $500^{\circ} \mathrm{C}$.

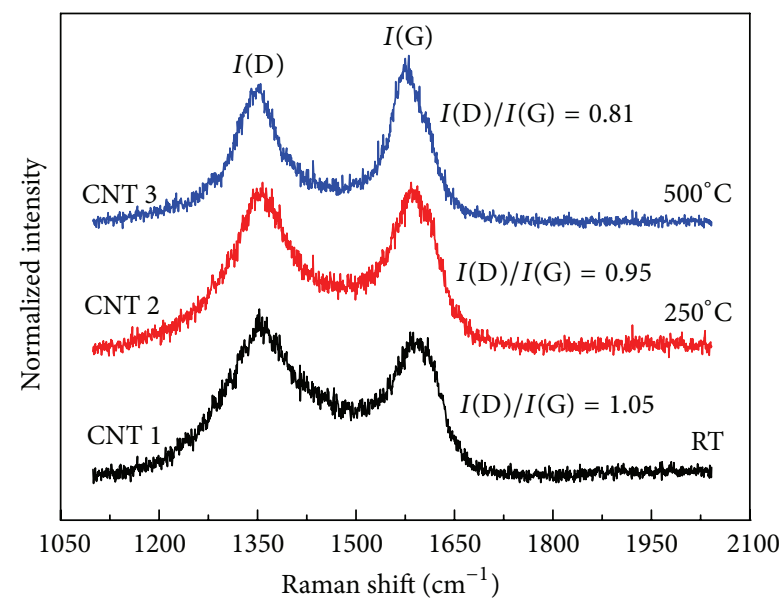

Figure 5: Raman spectra of CNTs grown on different C:Co composite films (inserted table shows the $I(\mathrm{D}) / I(\mathrm{G})$ ratios).

\section{Acknowledgment}

The authors would like to acknowledge the financial support from GLOBALFOUNDRIES Singapore Pte. Ltd.-EDB scholarship scheme.

\section{References}

[1] V. N. Popov, "Carbon nanotubes: properties and application," Materials Science and Engineering R, vol. 43, no. 3, 2004.

[2] D. J. Yang, Q. Zhang, G. Chen, S. F. Yoon, J. Ahn, S. G. Wang et al., "Thermal conductivity of multiwalled carbon nanotubes," Physical Review B, vol. 66, Article ID 165440, 6 pages, 2002.

[3] S. Ciraci, S. Dag, T. Yildirim, O. Gülseren, and R. T. Senger, "Functionalized carbon nanotubes and device applications," Journal of Physics Condensed Matter, vol. 16, no. 29, pp. R901R960, 2004.

[4] K. P. Yung, J. Wei, and B. K. Tay, "Formation and assembly of carbon nanotube bumps for interconnection applications," Diamond and Related Materials, vol. 18, no. 9, pp. 1109-1113, 2009.

[5] C. P. Deck and K. Vecchio, "Prediction of carbon nanotube growth success by the analysis of carbon-catalyst binary phase diagrams," Carbon, vol. 44, no. 2, pp. 267-275, 2006.

[6] C. C. Yap, D. Tan, C. Brun et al., "Impact of the CNT growth process on gold metallization dedicated to RF interconnect applications," International Journal of Microwave and Wireless Technologies, vol. 2, no. 5, pp. 463-469, 2010.

[7] Y. B. Zhang, S. P. Lau, L. Huang, and B. K. Tay, "Carbon nanotubes grown on cobalt-containing amorphous carbon composite films," Diamond and Related Materials, vol. 15, no. 1, pp. 171-175, 2006. 
[8] Y. Awano, S. Sato, M. Nihei, T. Sakai, Y. Ohno, and T. Mizutani, "Carbon nanotubes for VLSI: interconnect and transistor applications," Proceedings of the IEEE, vol. 98, no. 12, pp. 2015-2031, 2010.

[9] P. Zhang, B. K. Tay, and S. P. Lau, "Rapid thermal annealing study on the metal containing amorphous carbon films," Diamond and Related Materials, vol. 12, no. 10-11, pp. 2093-2098, 2003.

[10] A. T. T. Koh, J. Hsieh, and D. H. C. Chua, "Electron emission studies of CNTs grown on $\mathrm{Ti}$ and Ni containing amorphous carbon nanocomposite films," Applied Surface Science, vol. 256, no. 1, pp. 178-182, 2009.

[11] T. Takeno, H. Miki, T. Takagi, and H. Onodera, "Electrically conductive properties of tungsten-containing diamond-like carbon films," Diamond and Related Materials, vol. 15, no. 11-12, pp. 1902-1905, 2006.

[12] S. Sansongsiri, A. Anders, and B. Yotsombat, "Electrical properties of a-C: mo films produced by dual-cathode filtered cathodic arc plasma deposition," Diamond and Related Materials, vol. 17, no. 12, pp. 2080-2083, 2008.

[13] J. L. Endrino, D. Horwat, R. Gago et al., "Electronic structure and conductivity of nanocomposite metal ( $\mathrm{Au}, \mathrm{Ag}, \mathrm{Cu}, \mathrm{Mo})$ containing amorphous carbon films," Solid State Sciences, vol. 11, no. 10, pp. 1742-1746, 2009.

[14] N. Xu, H. T. E. Teo, M. Shakerzadeh, X. Wang, C. M. Ng, and B. K. Tay, "Electrical properties of textured carbon film formed by pulsed laser annealing," Diamond and Related Materials, vol. 23, pp. 135-139, 2012.

[15] C. W. Tan, S. Maziar, E. H. T. Teo, and B. K. Tay, "Microstructure and through-film electrical characteristics of vertically aligned amorphous carbon films," Diamond and Related Materials, vol. 20, no. 3, pp. 290-293, 2011.

[16] M. Shakerzadeh, N. Xu, M. Bosman et al., "Field emission enhancement and microstructural changes of carbon films by single pulse laser irradiation," Carbon, vol. 49, no. 3, pp. 10181024, 2011.

[17] D. W. M. Lau, D. G. McCulloch, M. B. Taylor et al., "Abrupt stress induced transformation in amorphous carbon films with a highly conductive transition phase," Physical Review Letters, vol. 100, no. 17, Article ID 176101, 2008.

[18] N. Y. Xu, H. T. Teo, X. C. Wang, A. Y. Du, C. M. Ng, and B. K. Tay, "Carbon metal composite film deposited using novel filtered cathodic vacuum arc technique," in Proceedings of the 61st Electronic Components and Technology Conference (ECTC '11), pp. 1234-1238, June 2011.

[19] J. Robertson, "Diamond-like amorphous carbon," Materials Science \& Engineering, vol. 37, no. 4-6, pp. 129-281, 2002.

[20] A. C. Ferrari and J. Robertson, "Interpretation of Raman spectra of disordered and amorphous carbon," Physical Review B, vol. 61, no. 20, pp. 14095-14107, 2000.

[21] G. Abrasonis, M. Krause, A. Mücklich, K. Sedlacková, G. Radnóczi, U. Kreissig et al., "Growth regimes and metal enhanced 6-fold ring clustering of carbon in carbon-nickel composite thin films," Carbon, vol. 45, no. 15, pp. 2995-3006, 2007.

[22] K. D. G. I. Jayawardena, Y. Y. Tan, J. Fryar et al., "Highly conductive nanoclustered carbon:nickel films grown by pulsed laser deposition," Carbon, vol. 49, no. 12, pp. 3781-3788, 2011.

[23] M. S. Dresselhaus, G. Dresselhaus, R. Saito, and A. Jorio, "Raman spectroscopy of carbon nanotubes," Physics Reports, vol. 409, no. 2, pp. 47-99, 2005.
[24] X. Sun, K. Li, R. Wu et al., "The effect of catalysts and underlayer metals on the properties of PECVD-grown carbon nanostructures," Nanotechnology, vol. 21, no. 4, Article ID 045201, 2010. 

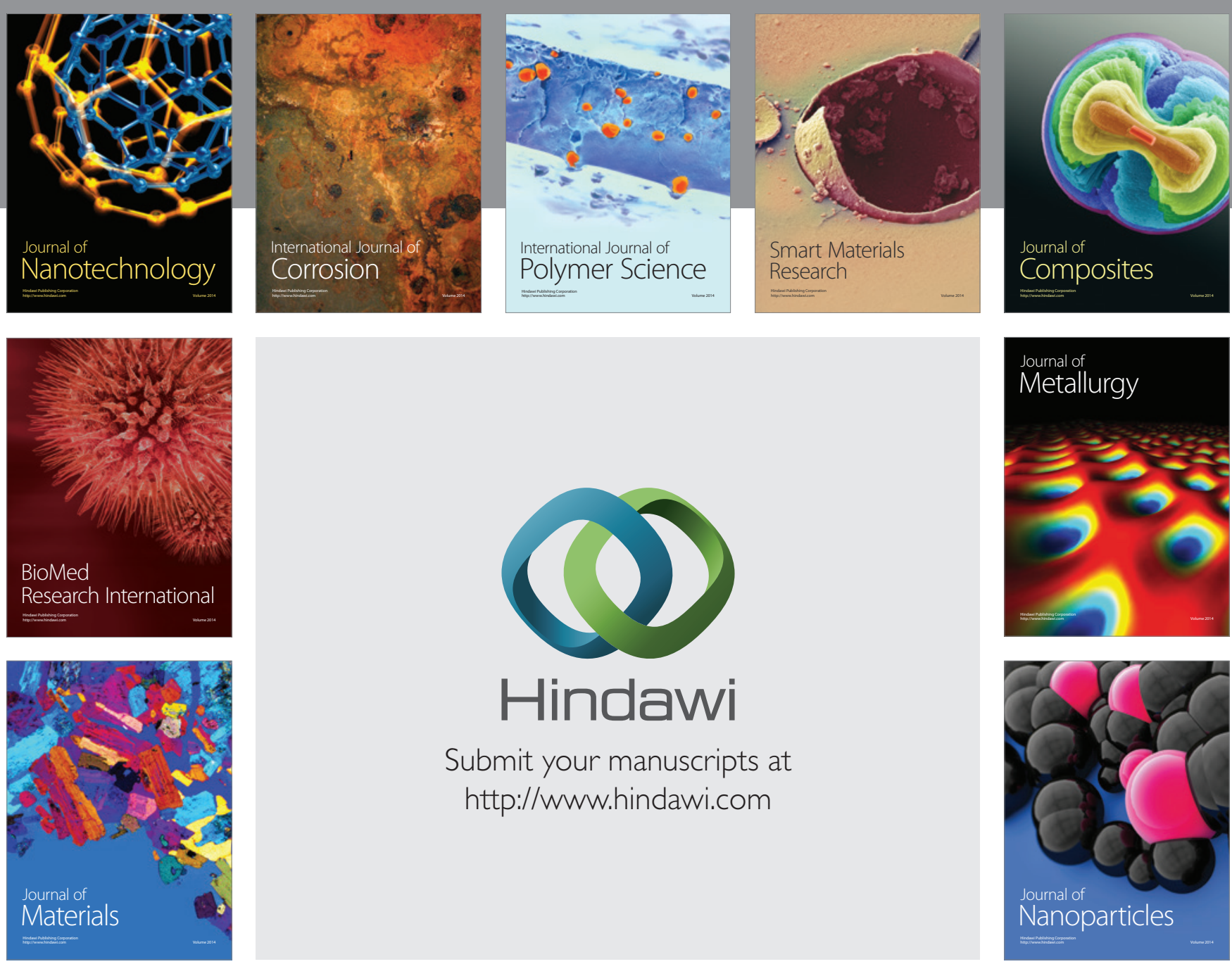

Submit your manuscripts at http://www.hindawi.com
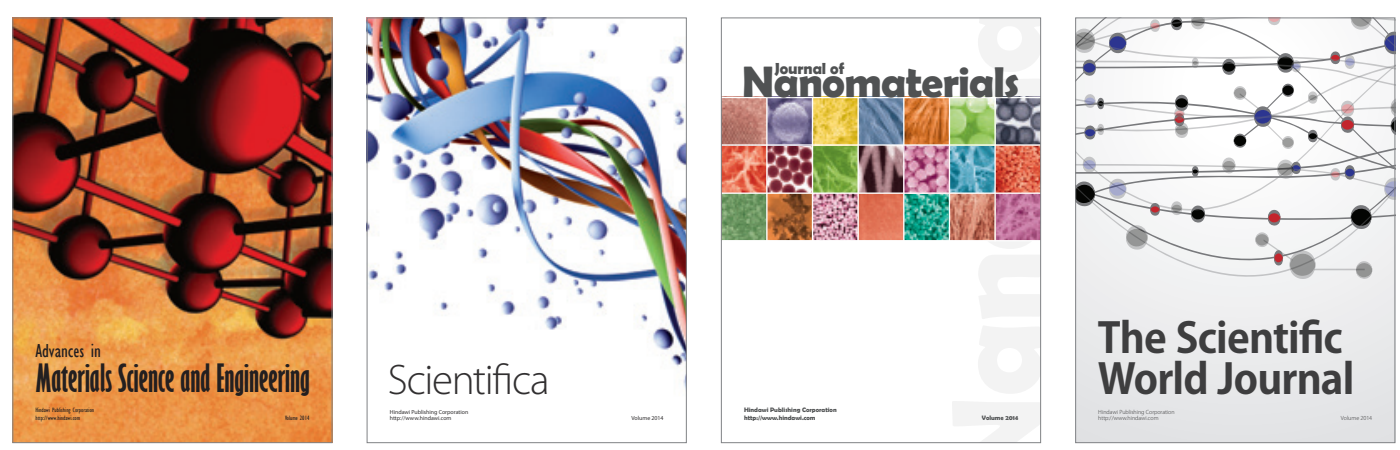

\section{The Scientific World Journal}
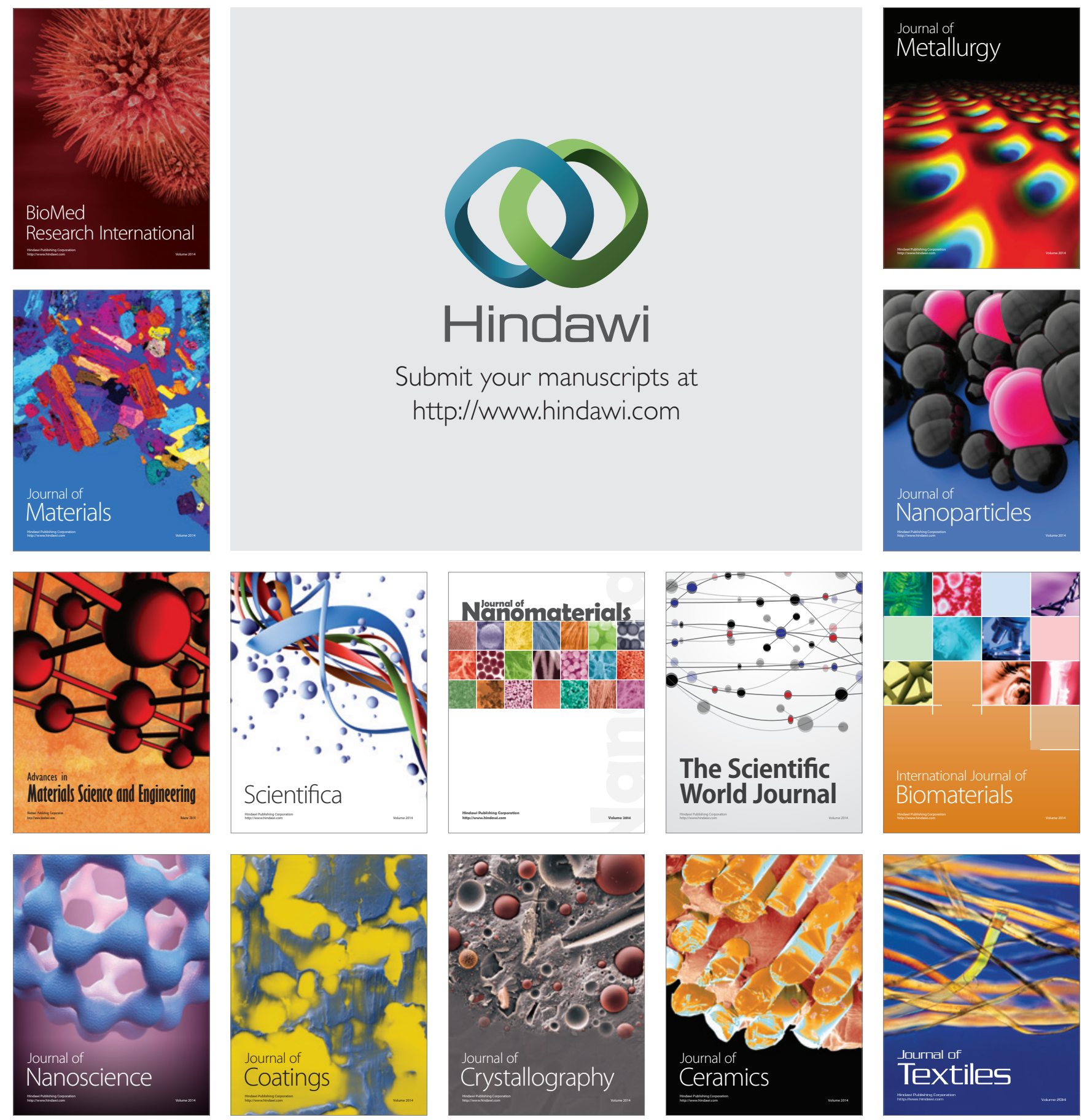